\title{
Gestão de portfólio de projetos como suporte a tomada de decisões de investimento em iniciativas de corporate venture capital
}

\author{
Alexander Prado Lara \\ Mônica Ramos Carneiro \\ Gertrudes Dandolini \\ Mestre em Engenharia de Produção - Universidade Federal de Santa Catarina (UFSC) - Brasil - alex@starta.com.br \\ Mestre em Administração Pública - Universidade Federal de Santa Catarina (UFSC) - Brasil - moni.carneiro@hotmail.com \\ Doutora em Engenharia de Produção - Universidade Federal de Santa Catarina (UFSC) - Brasil - gertrudes.dandolini@ufsc.br \\ João Arthur de Souza \\ Doutor em Engenharia de Produção - Universidade Federal de Santa Catarina (UFSC) - Brasil - jartur@gmail.com
}

\section{RESUMO}

Este artigo apresenta um estudo de aplicação da abordagem de Gestão de Portfólio de Projetos (GPP) para apoiar o processo de seleção de startups a investir, no contexto do Corporate Venture Capital (CVC). Conduzida pela metodologia Pesquisa-Ação, a investigação aplicou e avaliou métodos e técnicas de GPP em um contexto real, em que sua utilização orientou o processo de seleção da carteira de startups investidas por uma grande empresa do setor de software. O estudo sugere que GPP pode ser uma abordagem indicada para balizar o processo de análise e seleção de startups alvos de CVC, algo que a literatura aponta como um de seus maiores desafios. E em que pese ter sido baseado em apenas um caso e na formação inicial do portfólio, o artigo pode ajudar pesquisadores e consultores dedicados a temas ligados a CVC no desafio de gerenciar carteiras de investimento.

Palavras-chave: Corporate venture capital. Gestão de portfólio de projetos. Inovação. Corporate venturing.

\section{Portfolio management project as support for decision making in initiatives of investment by corporate venture capital}

\begin{abstract}
This paper presents a study about the implementation of the Portfolio Management Project approach to support the selection process of starups to be invested in the context of Corporate Venture Capital (CVC), by a large company in the software industry. The research was guided by Action Research methodology. The study is based on the literature that suggests the Portfolio Management Project approach to be the appropriate guide line in the process of analysis and targeting of startups for investments by CVC. And, in spite of being based on only one case, and in the initial phase of the portfolio creation, the study can help researchers and consultants dedicated to issues related CVC on the challenge of managing investment portfolios.
\end{abstract}

Keywords: Corporate venture capital. Project portfolio management. Innovation. Corporate venturing. 


\section{INTRODUÇÃO}

Esse artigo adota a definição de Chesbrough (2002), para quem o termo Corporate Venture Capital (CVC) designa não apenas um fundo privado criado/controlado por uma empresa madura com o propósito de realizar investimentos em projetos de inovação, mas especificamente quando tal investimento é realizado diretamente em uma startup externa. Essa definição exclui investimentos intermediados por gestores de fundos ou em unidades/projetos internos, exceto quando estes últimos já passaram por processos de spin-off e se tornaram empreendimentos independentes.

CVC é uma das várias atividades associadas ao chamado Corporate Venturing (SATHE, 2003; MORRIS; KURATKO; COVIN, 2008), por sua vez definido como o conjunto de estratégias e mecanismos usados por empresas maduras para renovação de sua oferta de produtos e serviços, quer seja através de criação de novos mercados, lançamento de novos produtos ou formação de unidades de negócio autônomas (ARRUDA et al, 2013).

As iniciativas de CV se dividem em internas ou externas à organização (SATHE, 2003), conforme resume o Quadro 1 - entendendo-se por internas o conjunto de atividades executadas por departamentos ou divisões da corporação.

Quadro 1 - Atividades Internas e Externas de Corporate Venturing

\section{Atividades Internas}

(i) Transformação de atividades de P\&D interna em novos negócios;

(ii) Criação de nova unidade autônoma;

(iii) Investimentos em atividades de risco dentro da companhia e que são desenvolvidas e gerenciadas por seus empregados.

\section{Atividades Externas}

(i) Fusões e aquisições;

(ii) Alianças estratégicas;

(iii) Joint-ventures;

(iv) Acordos de licenciamento;

(v) UTILIZAÇÃO DE CORPORATE VENTURE CAPITAL;

(vi) Atividades externas de P\&D;

(vii) Criação de novas empresas;

(viii) Spin-In, Spin-Out e divestures

Fonte: Adaptado de Sathe (2003) e Arruda et al (2013 p. 141)

Ou seja, Corporate Venture Capital é uma dentre uma dezena de possibilidades para se adotar estratégias de CV. Por essa razão não se limita à busca de retorno financeiro e incorpora objetivos estratégicos para a corporação, dentre os quais Arruda et al (2013) destacam: (i) suporte a estratégias de crescimento; (ii) acesso a novos mercados; (iii) ampliação da cadeia de valor (desenvolvimento do ecossistema); (iv) expansão do escopo de operações e conhecimentos; (v) aplicação de novas ideias e formas de inovação; (vi) desenvolvimento de novas capacidades (instrumento de inovação radical); (vii) obtenção de ganhos financeiros; (viii) aprender sobre novos produtos e serviços; (ix) alternativa ao negócio principal; (x) diversificação de risco; (xi) promoção da imagem da empresa junto ao mercado e investidores; e (xii) geração de novos negócios.

A despeito de empresas líderes da Europa e EUA investirem em atividades Corporate Venturing (CV) desde a década de 1970, a adoção de suas práticas é algo recente e ainda limitado a uma pequena parcela do conjunto de empresas maduras (CHESBROUGH, 2002; SATHE, 2003; ARRUDA et al, 2013). Entretanto, a intensificação da competição global e a aceleração das mudanças tecnológicas torna previsível uma intensificação desse movimento (SATHE, 2003; KURATKO; COVIN; GARRETT, 2008). Até mesmo em países emergentes, como Brasil e China, esse tema já começa a fazer parte da agenda empresarial (ARRUDA et al, 2013).

Particularmente sobre CVC, já há um número crescente de corporações direcionando recursos para investimento em startups ${ }^{1}$ (QUITTNER, 2014; POZIN, 2014); e se juntando a empresas como Lucent, Intel, Cisco, Microsoft, Qualcomm, Merck e Panasonic, que adotam essa estratégia de forma sistemática (CHESBROUGH, 2002). 
A escolha de critérios e processos que balizem decisões de investir num dado conjunto de startups é apontado por Chesbrough (2002) como um dos principais desafios para as corporações que adotam estratégias de CVC.

Este documento apresenta uma síntese dos principais resultados obtidos por uma pesquisa científica executada em paralelo ao processo de seleção de startups ao programa de corporate venture capital de uma das maiores empresas do setor de software do estado de Santa Catarina. O presente artigo e a pesquisa que lhe deu origem sugerem a utilização da abordagem de Gestão de Portfólio de Projetos (GPP) para conduzir o processo de descarte e seleção de startups.

$\mathrm{Na}$ sequência do artigo, as seções 2 e 3 apresentam um registro sucinto do arcabouço teórico sobre CVC e GPP, respectivamente. A seção 4 apresenta os resultados do estudo de caso. Finalmente, a seção 5 registra as principais conclusões e discute sobre perspectivas de futuros trabalhos em temas correlatos.

\section{CORPORATE VENTURING E CORPORATE VENTURE CAPITAL}

Historicamente, o esforço de conceber e comercializar uma invenção ou criar novas maneiras de satisfazer necessidades e desejos de consumidores esteve vinculado à visão de empreendedores individuais e empresas nascentes - especialmente em setores intensivos em tecnologia (ANTHONY, 2012).

De uma forma geral, empresas maduras têm muitas dificuldades para inovar e frequentemente são taxadas de lentas, burocráticas, inibidoras da criatividade, do risco e da experimentação (HISRICH; PETERS, 1986; MANDEL, 2011). Tais dificuldades são resultado do maior comprometimento das organizações com os produtos e tecnologias existentes, com a melhoria da eficiência operacional e com a geração de lucro a partir dos seus atuais ativos, clientes e canais de distribuição. Ou seja, grandes corporações inovam menos do que poderiam simplesmente por não estarem moldadas para fazê-lo, mas para fazer bem, e cada vez melhor, aquilo que já vêm sendo feito (HISRICH; PETERS, 1986).

A despeito de inovação e criação de novos negócios ainda serem temas mais comumente associados a startups, há um número crescente de especialistas apontando para o desejável, necessário ou efetivo protagonismo das empresas maduras na seara das inovações (HISRICH; PETERS, 1986; CHESBROUGH, 2002; KURATKO; COVIN; GARRET, 2008, 2009; IRELAND; COVIN; KURATKO, 2009; MANDEL, 2011; ANTHONY, 2012).

Anthony (2012) associa esse protagonismo a uma nova era da inovação, baseada em ecossistemas sob a liderança de grandes corporações - como aqueles em torno da Google (plataforma Android/ Play Store); da Apple (Apple Store) e da IBM (Smart Cities).

\subsection{Razões para se Investir em Startups}

Enquanto no Venture Capital (VC) a motivação primária para se investir em startups é financeira, ou seja, a perspectiva de alto retorno a partir de um investimento de alto risco, no Corporate Venture Capital (CVC) o julgamento deve ser feito sob outras perspectivas, em particular alavancagem do crescimento da empresa, quer seja promovendo os atuais ou lançando novos negócios (CHESBROUGH, 2002).

Figura 1- Estratégias de Investimento em Startups

\section{Objetivo do investimento}

Estratégico

\section{Motriz}

Alta

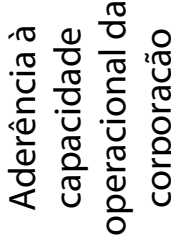

Baixa

\begin{tabular}{|c|}
\hline $\begin{array}{c}\text { Motriz } \\
\text { Alavancar estratégias ligadas aos } \\
\text { negócios atuais }\end{array}$ \\
\hline $\begin{array}{c}\text { Facilitadora } \\
\text { Complementar estratégias ligadas } \\
\text { aos negócios atuais }\end{array}$ \\
\hline
\end{tabular}

Financeiro

Emergente

Explorar novos negócios em potencial

\section{Passiva}

Apenas prover retorno financeiro

Fonte: Traduzido de Chesbrough (2002, p. 7) 
Chesbrough (2002) classifica as estratégias corporativas de investimento em startups em quatro tipos ou propósitos: (i) motriz (driving); (ii) emergente (emergent); (iii) facilitadora (enabling) ou (iv) passiva (passive), criados a partir da análise dos objetivos do investimento (se estratégico ou financeiro) e do grau de aderência do startup à capacidade operacional da corporação, conforme ilustra a Figura 1.

Com exceção da estratégia "passiva", que se alinha à mesma lógica financista do VC, cada uma das outras três permite à empresa traçar diferentes táticas para se obter retorno sobre o investimento e promover crescimento de seus negócios - atuais ou futuros -, como exemplificado no Quadro 2.

Esse framework ajuda a justificar e classificar as estratégias de investimento em startups e serve como ponto de partida, em que pese ser insuficiente para endereçar todas as questões impostas pelo desafio citado na introdução desse artigo: definir critérios e mecanismos objetivos para suporte à decisão de descartar, selecionar e montar um portfólio de startups.

Quadro 2 - Estratégias de Investimento e Táticas para Promover Crescimento dos Negócios

\begin{tabular}{|c|c|c|}
\hline Estratégia & Táticas & Exemplo \\
\hline Motriz & $\begin{array}{l}\text { Promover um padrão tecnológico } \\
\text { de interesse da organização atra- } \\
\text { vés do investimento em startups } \\
\text { que desenvolvam produtos ou } \\
\text { serviços que estimulem a adoção } \\
\text { de tal padrão. }\end{array}$ & $\begin{array}{c}\text { Microsoft investiu em empresas } \\
\text { que adotavam a sua Plataforma } \\
\text {.NET. }\end{array}$ \\
\hline Facilitadora & $\begin{array}{c}\text { Estimular a demanda de produ- } \\
\text { tos da organização quando se } \\
\text { investe em startups com soluções } \\
\text { complementares e cuja adoção } \\
\text { aumenta a demanda das soluções } \\
\text { da corporação. }\end{array}$ & $\begin{array}{l}\text { Intel investe em aplicações que } \\
\text { aumentam a demanda pelos seus } \\
\text { processadores. }\end{array}$ \\
\hline \multirow{4}{*}{ Emergente } & $\begin{array}{c}\text { Estimular spin-off de empreendi- } \\
\text { mentos que explorem tecnologias } \\
\text { subutilizadas e/ou não estratégi- } \\
\text { cas para a organização. }\end{array}$ & $\begin{array}{c}\text { Lucent investe em empresas } \\
\text { construídas a partir da exploração } \\
\text { de tecnologias desenvolvidas por } \\
\text { ela, mas identificadas como não } \\
\text { centrais. }\end{array}$ \\
\hline & $\begin{array}{c}\text { Experimentar novas possibilida- } \\
\text { des, em empreendimentos que } \\
\text { desenvolvam soluções/negócios } \\
\text { desalinhados ou mesmo conflitan- } \\
\text { tes com os da corporação. }\end{array}$ & $\begin{array}{l}\text { Cisco investe em tecnologias que } \\
\text { mais tarde ela pode adquirir e } \\
\text { incorporar internamente. }\end{array}$ \\
\hline & $\begin{array}{l}\text { Desenvolver tecnologias "backup", } \\
\text { que sirvam como espécie de segu- } \\
\text { ro em relação à direção tecnológi- } \\
\text { ca atual. }\end{array}$ & $\begin{array}{c}\text { Intel investiu em uma empresa } \\
\text { que desenvolvia uma tecnologia } \\
\text { de rede com potencial de } \\
\text { suplantar aquela que a Intel } \\
\text { apostava. }\end{array}$ \\
\hline & $\begin{array}{l}\text { Explorar nichos de mercado } \\
\text { "virgens", através de empresas que } \\
\text { atendam clientes desses novos } \\
\text { mercados, como forma de obter } \\
\text { indicadores do potencial de tais } \\
\text { mercados. }\end{array}$ & $\begin{array}{c}\text { Panasonic investiu em startups } \\
\text { que atuavam na convergência } \\
\text { de home-computer e } \\
\text { entretenimento. }\end{array}$ \\
\hline
\end{tabular}

Fonte: Adaptado e Traduzido de Chesbrough (2002, p. 10-11)

\section{GESTÃO DE PORTFÓLIO DE PROJETOS}

Gestão de Portfólio de Projetos (GPP) é um conjunto de processos, método e técnicas para analisar e gerenciar coletivamente o conjunto de projetos atuais e futuros - com base em diferentes variáveis. A GPP diz respeito à alocação de recursos e ao processo de selecionar quais projetos investir, priorizar ou mesmo abandonar (COOPER; EDGETT; KLEINSCHMIDT, 2000, 2001).

Além de escolher projetos individuais com maior potencial de dar origem a produtos vencedores, o processo de GPP avalia a carteira de projetos como um todo e os investimentos que a empresa faz na área de P\&D\&l (Pesquisa, Desenvolvimento e Inovação). É vista como uma abordagem 
fundamental para o sucesso das atividades relacionadas à inovação e desenvolvimento de novos negócios (COOPER; EDGETT; KLEINSCHMIDT, 2000; COOPER; EDGETT, 2006; URHAHN; SPIETH, 2014).

A GPP persegue três objetivos (COOPER; EDGETT; KLEINSCHMIDT, 2000; COOPER; EDGETT, 2006): (i) maximizar o valor do portfólio de produtos (existente e futuros) em termos de retorno financeiro ou outro parâmetro mensurável; (ii) promover balanceamento entre projetos de menor ou maior complexidade, risco, prazo, escopo ou entre diferentes tecnologias e mercados, por exemplo; e (iii) alinhar o portfólio com a estratégia geral do negócio (visão).

Para cada um desses objetivos, há várias técnicas e abordagens - tanto quantitativas quanto qualitativas - cada qual com um conjunto de pontos fortes e fracos. O desafio dos gestores não é apenas escolher quais técnicas adotar, mas o fato de que nenhum método isolado é capaz de cumprir com os três objetivos anteriormente assinalados (COOPER; EDGETT, 2006).

\subsection{Maximizando o valor do portfólio}

Maximizar o valor do portfólio é a proposta de algumas técnicas da GPP, dentre as quais a literatura destaca (COOPER; EDGETT; KLEINSCHMIDT, 2000; 2001; COOPER; EDGETT, 2006):

(i) Net Present Value (NPV) ou valor presente líquido (VPL), que poderá ser comparado a um valor mínimo que precisa se excedido ou usado para classificar os projetos.

(ii) Expected Commercial Value (ECV), ou valor comercial esperado, é uma variante do VPL, mas inclui uma árvore de decisão e análises probabilísticas. Busca identificar o valor de um projeto a partir de sua separação em estágios e seus prováveis resultados.

(iii) Checklists, são listas de verificação do tipo "Sim/Não" usadas para avaliar um projeto e para descartar aqueles que atingirem uma ou mais respostas "não". O Quadro 3 mostra um exemplo de checklist.

(iv) Scoring Models. Os projetos são avaliados através de um conjunto de critérios e pesos associados. As notas associadas a cada critério são somadas e usadas para formar um ranking de projetos a serem priorizados. Os critérios são organizados de forma a cobrir aspectos como alinhamento estratégico, vantagem competitiva do produto, atratividade de mercado, risco $x$ potencial de retorno etc.

Há limitações associadas a todos estes métodos. Ferramentas estritamente financeiras podem errar por uma razão simples: dados financeiros frequentemente se mostram errados. Checklists podem ser bastante eficazes para descartar, mas difíceis de serem usados para priorizar projetos. Scoringmodels são muito populares por incorporarem múltiplas preocupações, inclusive financeiras, mas consomem mais tempo e dão a falsa impressão de ser um método preciso (COOPER; EDGETT; KLEINSCHMIDT, 2001).

Quadro 3- Lista de verificação típica, com critérios obrigatórios para seleção de projetos

\section{$[\sqrt{ }]$ Alinhamento estratégico}

O projeto proposto está alinhado com a estratégia e com a visão da empresa

\section{$[\sqrt{ }]$ Viabilidade técnica}

Há uma razoável probabilidade de viabilidade técnica. Ou seja, é possível que a empresa consiga desenvolver/produzir o produto proposto. Não há razões para acreditar que não seja possível fazê-lo. $[\sqrt{ }]$ Razões competitivas

Existe uma razão de ordem competitiva para tocar o projeto. Ou porque é uma necessidade defensiva, um produto estratégico ou com claras vantagens competitivas (único; superior; etc.)

\section{$[\sqrt{ }]$ Atratividade de mercado}

O mercado é grande e crescente; a demanda pelo produto é significante; os concorrentes são vulneráveis

$[\sqrt{ }]$ Vantagem competitiva sustentável

O produto tem uma vantagem que pode ser protegida ou barreira de entrada a novos concorrentes $[\sqrt{ }]$ Sinergias

O projeto potencializa as (ou é construído a partir das) competências essenciais ou pontos fortes da empresa (tecnológicos; mercadológicos ou de produção)

[ $\sqrt{ }]$ Empecilhos

Não há nenhum empecilho evidente ou alguma variável conhecida que possa fazer o projeto ser abortado 


\subsection{Balanceamento do Portfólio}

Diz respeito a promover uma melhor diversificação de projetos, em termos de alguns parâmetroschave. Projetos de longo $\mathrm{x}$ curto prazo, alto $\mathrm{x}$ baixo risco; distribuídos entre diferentes mercados ou baseados em diferentes tecnologias (COOPER; EDGETT; KLEINSCHMIDT, 2000).

A ferramenta mais difundida é o Diagrama de Bolhas (COOPER; EDGETT; KLEINSCHMIDT, 2001), que apresenta quatro quadrantes, a partir de duas dimensões de análise, onde são desenhadas figuras representando os projetos. O diagrama (Figura 1) também permite visualizar outras informações através do uso de cores, formatos ou tamanho dos objetos desenhados.

Figura 1- Exemplo de diagrama de bolhas para análise do portfólio de produtos e projetos

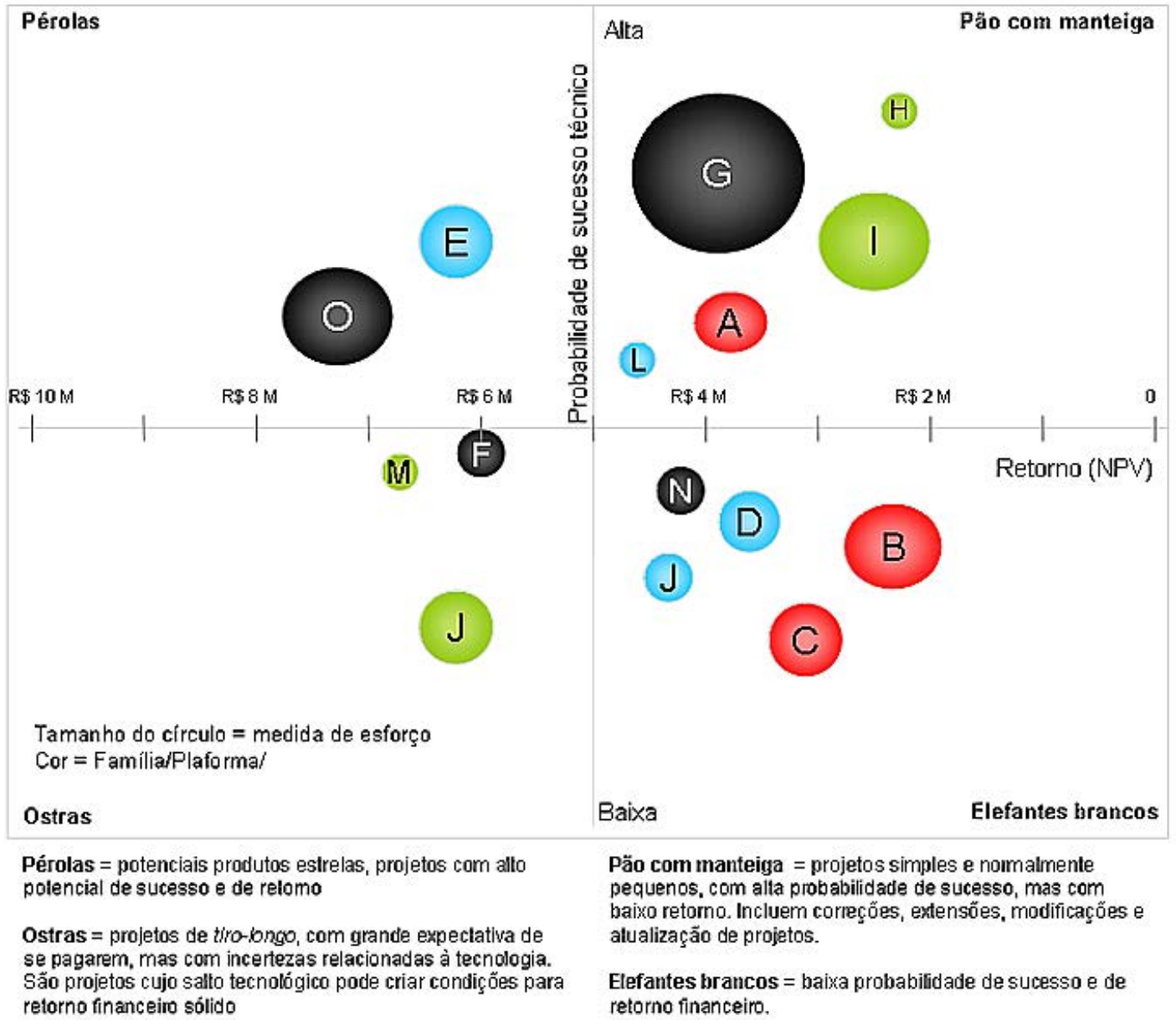

Fonte: Adaptado de Cooper, Edgett e Kleinschmidt (2001, p. 58), Cooper e Edgett (2006, p. 10).

Diferentes aspectos podem ser analisados a partir da escolha das dimensões consideradas no diagrama e o valor atribuído a cada dimensão pode considerar vários critérios de análises (COOPER; EDGETT; KLEINSCHMIDT, 2001).

Diagrama de bolhas não é um método de priorização, mas de visualização dos projetos e suporte ao processo de decisão. Ao mostrar a distribuição dos projetos entre os quadrantes, permite que se verifique se a distribuição está em linha com os propósitos da empresa. A versão mais popular é a variante risco-retorno (Figura 1). Uma dimensão é o NPV e a outra a probabilidade de sucesso comercial e técnico. Algumas variantes, como o diagrama "Facilidade versus Atratividade", procuram eliminar a necessidade de se obter dados financeiros precisos (COOPER; EDGETT; KLEINSCHMIDT, 2001; COOPER; EDGETT, 2006).

\subsection{Alinhando o portfólio à estratégia da empresa}

Missão, visão e estratégia do negócio devem orientar a alocação dos recursos. Ou seja, os projetos e produtos do portfólio devem refletir estes direcionadores (COOPER; EDGETT; KLEINSCHMIDT, 
2000). Em outras palavras, o portfólio deve ser consistente com a estratégia empresarial e refletir as prioridades de investimento traçadas por ela (COOPER; EDGETT; KLEINSCHMIDT, 2001). Por exemplo, uma organização que quer ser reconhecida como inovadora deve buscar um portfólio com produtos e soluções inovadoras, da mesma forma que uma empresa que traçou planos de investir prioritariamente em certos setores estratégicos precisa contar com projetos a eles endereçados. Cooper e Edgett (2006) sugerem duas possíveis abordagens para alinhamento dos projetos à estratégia da empresa:

- Bottom-Up: seleção de projetos, a partir de um scoring model criado de forma a pontuar a aderência do projeto à estratégia da empresa.

- Top-Down: seguindo o princípio de que "implementar uma estratégia = gastar dinheiro em projetos específicos", os recursos são primeiro separados de acordo com os alvos de dispêndio (setores; tecnologias, por exemplo), em espécies de "envelopes" estratégicos, e depois distribuídos entre os projetos candidatos.

\section{ESTUDO DE CASO}

A investigação seguiu a estratégia metodológica de Pesquisa-Ação (PA), tipo de pesquisa social, empírica, que acontece em paralelo com a resolução de um problema (COUGHLAN; COGHLAN, 2002; THIOLLENT, 1996). Além de resultados em termos de produção de conhecimento, de uma pesquisaação também se espera do pesquisador o papel de agente ativo na mudança do contexto pesquisado, o que permite cumprir tanto com o objetivo de geração de conhecimento científico quanto o de melhorar a compreensão dos problemas abordados e das soluções adotadas (THIOLLENT, 1996; COUGHLAN; COGHLAN, 2002).

A adoção da PA como estratégia de condução da pesquisa e coleta de dados foi naturalmente favorecida em virtude de dois dos autores terem sido contratados como consultores, pela Corporação, justamente para ajudá-la a planejar e executar suas atividades de CVC.

A pesquisa foi conduzida ao longo do segundo semestre de 2014, quando os pesquisadores ajudaram a conceber e coordenaram todas as atividades ligadas ao processo de seleção do programa de CVC da Corporação. Além dos dois pesquisadores, participaram ativamente do projeto dois profissionais de nível gerencial e um diretor da empresa contratante, e uma dezena de outros profissionais ligados à Corporação tiveram contribuições pontuais.

\subsection{Apresentação do Inove Senior}

Lançado no final de 2014, o Inove Senior é o programa de investimento em startups de uma das maiores empresas brasileiras desenvolvedoras de softwares de gestão. Com sede em Blumenau/ SC, a Senior enxergava nessa iniciativa um mecanismo para diversificar seu portfólio de negócios, especialmente através da inserção no mercado de inovações que dificilmente seriam concebidas/ desenvolvidas por ela própria - quer seja por não estarem estreitamente vinculadas ao seu planejamento estratégico - ao seu core business, ou baseadas em conhecimentos não disponíveis na organização.

A ideia inicial era selecionar e investir em até 10 startups (existentes ou a serem criadas), que passariam por um programa inspirado no modelo de incubação corporativa (GASSMANN; BECKER, 2006). Com duração de nove meses, tanto empreendedores quanto seus empreendimentos receberiam capacitação, apoio técnico, econômico, financeiro e logístico para amadurecimento do projeto - do desenvolvimento das soluções à validação dos modelos de negócio junto a potenciais clientes. As startups contariam com a infraestrutura da Senior, incluindo sua força de vendas, e de mentores e especialistas contratados pela corporação para executarem o Programa, que se daria na cidade de Florianópolis/SC.

Ao final do Programa, os empreendimentos que cumprissem com as expectativas neles depositadas teriam recebido até $\mathrm{R} \$ 240$ mil em investimentos financeiros, além de cerca de $\mathrm{R} \$ 50 \mathrm{mil}$ em serviços. Das empresas destacadas a Senior se tornaria sócia, e buscaria fazer novos investimentos - para escalar rapidamente o (seu) novo empreendimento.

\subsection{O Processo de seleção}

Dos cerca de 260 projetos inscritos no Programa, aproximadamente 60 deles foram considerados 
elegíveis, dos quais 30 foram classificados como potencialmente interessantes, dentre os quais foram selecionados 17 projetos para apresentação oral, o que ajudou a coletar dados adicionais e balizar a efetiva seleção dos 10 projetos a investir. Em cada etapa do processo de seleção, diferentes critérios e métodos de GPP foram utilizados.

\subsubsection{De 260 para 60:Triagem}

Esta etapa consistiu na simples conferência dos dados submetidos ao sistema de inscrição. Candidatos que não enviaram todos os dados considerados críticos para a avaliação dos projetos foram sumariamente descartados. Ou seja, nessa etapa não foram feitas análises dos projetos em si.

\subsubsection{De 60 para 30: Filtro Inicial}

O objetivo dessa etapa foi eliminar projetos não aderentes ao conjunto de características mínimas desejáveis nos empreendimentos, tanto em termos de avaliação preliminar quanto do alinhamento aos interesses da Corporação. Para tanto, um checklist foi construído (vide Quadro 4), contra o qual os projetos foram confrontados. Uma resposta negativa a qualquer uma das perguntas contidas na lista gerava o descarte do projeto.

\section{Quadro 4 - Checklist (Características Obrigatórias)}

\section{Avaliação Preliminar}

Uma oportunidade de negócio ficou minimante caracterizada (problema/necessidade insatisfeita; + mode-

lo de negócio); e não apenas uma ideia de produto/serviço?

A equipe proponente parece ter as competências mínimas (técnicas e de gestão) para liderar o novo empreendimento, mesmo que apenas nas fases iniciais?

O negócio proposto ou alguma possível variação dele parece ter potencial de escala?

O empreendimento cumpre com preceitos éticos?

Há uma inovação tecnológica ou no modelo de negócio, mesmo que não seja radical/disruptiva?

Alinhamento às estratégias da Corporação

A ideia de negócio está voltada para $\mathrm{B} 2 \mathrm{~B}$ ou $\mathrm{B} 2 \mathrm{~B} 2 \mathrm{C}^{2}$ ?

A tecnologia e o produto propostos fazem sentido para a Corporação (TIC ou Automação)?

O mercado-alvo atual está de alguma forma alinhado a alguma das verticais de negócio da Corporação ou a algum nicho que pode ser explorado pela sua força de vendas?

Fonte: Elaborado pelos autores (2016)

\subsubsection{De 30 para 17: Análise e Seleção}

Essa etapa consistiu em buscar os 20 melhores projetos, número limite de startups que seriam convidadas a participar das fases presenciais do processo de seleção. A seleção se deu a partir da análise individual dos projetos selecionados para essa etapa e preenchimento de uma ficha de avaliação dos projetos composta por sete quesitos, sendo o último deles uma síntese dos outros seis (Quadro 5).

A ficha de avaliação foi uma adaptação do método de scoring model, com substituição de critérios objetivos (notas e pesos) por uma análise mais subjetiva - considera mais adequada às incertezas do contexto das startups avaliadas.

O preenchimento da ficha foi feito com base nas informações submetidas ao sistema de inscrição e coletadas através de entrevistas com os empreendedores (por telefone). 
Quadro 5 - Ficha de Avaliação dos Projetos

\begin{tabular}{|l|l|}
\hline \multicolumn{1}{|c|}{ QUESITO } & \multicolumn{1}{c|}{ VALORES } \\
\hline Grau de amadurecimento do empreendimento & Ideia | Protótipo| Iniciante | Emergente \\
\hline Potencial de mercado & Baixo | Médio | Alto \\
\hline Equipe: capacidade técnica & Baixo | Médio | Alto \\
\hline Equipe: perfil empreendedor & Baixo | Médio | Alto \\
\hline Grau de inovação da proposta & Baixo | Médio | Alto \\
\hline $\begin{array}{l}\text { Aderência aos mercados (clientes atuais ou potenciais) e à } \\
\text { capacidade operacional da Corporação }\end{array}$ & Baixo | Médio | Alto \\
\hline $\begin{array}{l}\text { Avaliação GERAL } \\
\text { (impressão geral considerando todos os critérios acima) }\end{array}$ & Ruim | Razoável | Promissor | Excelente \\
\hline
\end{tabular}

Fonte: Elaborado pelos autores (2016)

Após algumas rodadas de discussão e revisão das fichas de avaliação, foram selecionadas as 17 startups finalistas, apenas aquelas cujo quesito "Avaliação Geral" foi marcado como "promissor ou "Excelente".

\subsubsection{Conhecendo os 17 finalistas: Classificação}

As startups finalistas participaram de um workshop de dois dias, que perseguiu dois objetivos: (i) conhecer de perto os empreendedores e projetos; e (ii) capacitá-los e prepará-los para a banca final de seleção.

Como resultado do primeiro desses objetivos, as fichas de avaliação das startups foram revisadas e completadas com os quesitos listados no Quadro 6.

Quadro 6 - Variáveis Adicionais para Avaliação dos Projetos

\begin{tabular}{|c|c|}
\hline Variável & Valores \\
\hline Análise de Risco versus Potencial de Retorno & Alto | Médio|Baixo \\
\hline Facilidade de implementação/prazo de maturação & Alta | Media | Baixa \\
\hline Atratividade (tecnológica ou mercadológica) & Alta | Media |Baixa \\
\hline Tipo de investimento (CHESBROUGH, 2002, p. 7,10,11) & \begin{tabular}{|l|l|} 
Estratégico | Financeiro \\
\end{tabular} \\
\hline Tática de Crescimento (CHESBROUGH, 2002, p. 7,10,11) & 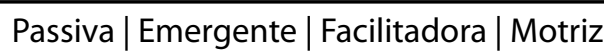 \\
\hline
\end{tabular}

Fonte: Elaborado pelos autores (2016)

Também como preparação para a fase seguinte, quando os projetos precisariam ser comparados entre si, foi construído um gráfico de bolhas "Capacidade versus Atratividade", a partir da síntese das informações contidas na ficha de avaliação. 
Figura 3 - Gráfico de Bolha "Capacidade versus Atratividade" dos 20 projetos finalistas

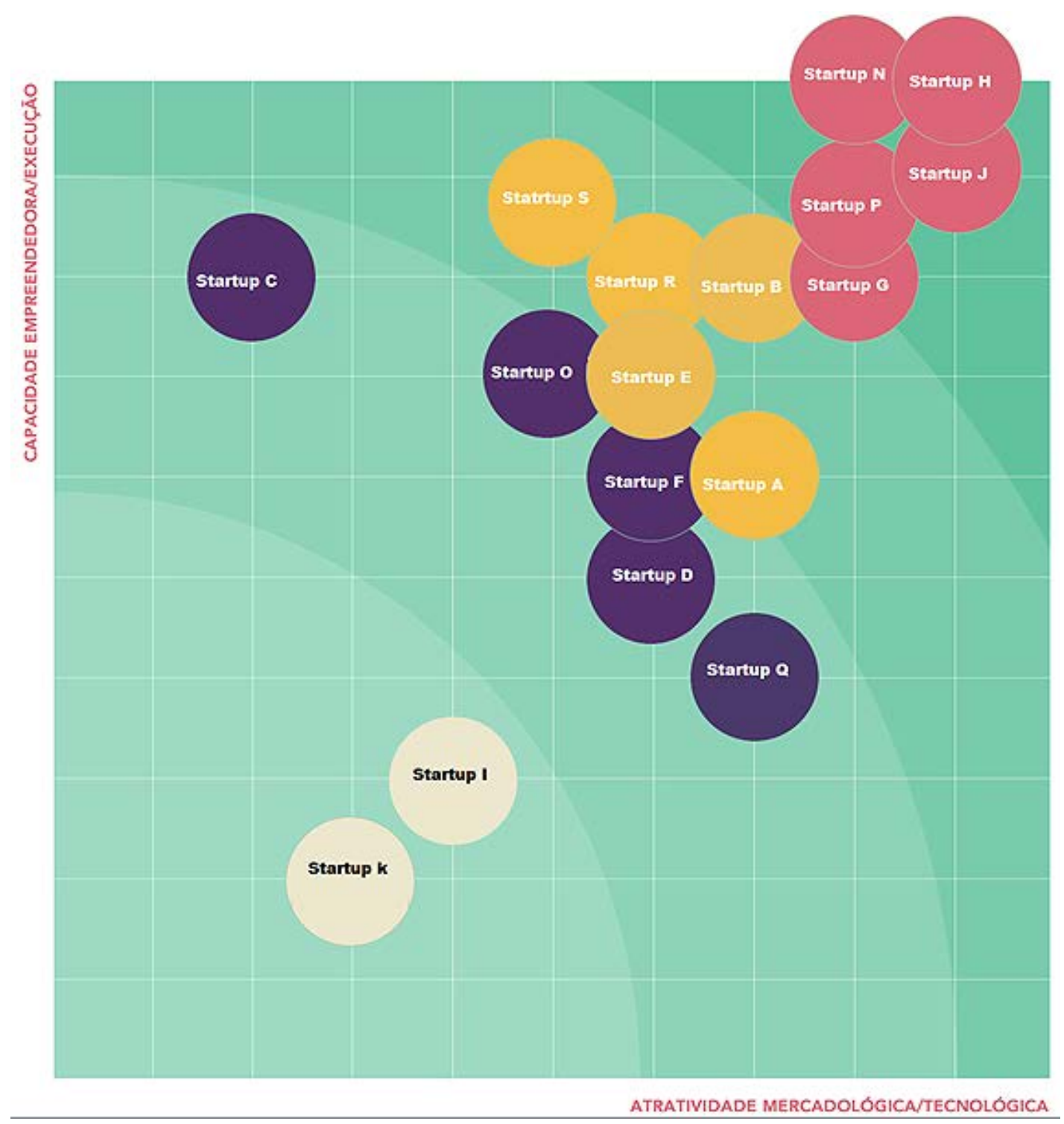

Fonte: Elaborado pelos autores (2016)

\subsubsection{De 17 para 10: A Formação do Portfólio}

O desafio adotado pela Corporação, nessa fase, não foi simplesmente o de comparar projetos e escolher os 10 melhores, mas construir um portfólio alicerçado nos seguintes pilares:

(i) Balanceado em termos de análise de investimento (risco versus potencial de retorno);

(ii) Que não deixasse de fora os melhores startups, mesmo que se tivesse que abrir mão de algum projeto interessante;

(iii)Que não fizesse apostas ruins, mesmo que se permitisse apostas com grau elevado de incerteza;

(iv) Diversificado, com apostas em diferentes setores e tecnologias.

A estratégia usada para promover o balanceamento do portfólio foi top-down, com definição de três "envelopes" estratégicos (Quadro 7). A escolha da estratégia top-down segue recomendação de McGrath (2000); Vähäniitty e Rautiainen (2005); Chao e Kavadias (2008); Lara e Cheng (2009) e Allman, Can e You (2012), que a consideram mais adequada à gestão de portfólios de novos produtos de software. 
Quadro 7 - Envelopes Estratégicos usados para Balanceamento do Portfólio

\begin{tabular}{|c|c|c|}
\hline CONSERVADOR & MÉDIO & ARROJADO \\
$\begin{array}{c}\text { Baixo risco (tecnológico e/ou } \\
\text { mercadológico), fácil levar ao } \\
\text { mercado ou acoplar aos produtos } \\
\text { da Corporação. Geralmente baixo } \\
\text { grau de inovação e/ou potencial } \\
\text { de retorno do investimento }\end{array}$ & $\begin{array}{c}\text { Meio termo entre conservador e } \\
\text { arrojado. }\end{array}$ & $\begin{array}{c}\text { Alto grau de inovação ou comple- } \\
\text { xidade (tecnológica ou merca- } \\
\text { dológica). Tende a ter alto risco } \\
\text { e potencial de retorno sobre o } \\
\text { investimento4. }\end{array}$ \\
\hline 3 ou 4 projetos & & 3 ou 4 projetos \\
\hline
\end{tabular}

Fonte: Elaborado pelos autores (2016)

Para classificar e selecionar os projetos em cada "envelope", foi utilizado o método de "scoring model", a partir de cinco critérios (Quadro 8) avaliados durante a apresentação dos 17 projetos finalistas a uma banca composta por diretores e conselheiros da Corporação. Os avaliadores atribuíam para cada quesito as notas 0 (ruim), 1 (regular) ou 2 (bom). A soma de todos os quesitos de todos os avaliadores representava a pontuação de cada empreendimento.

Por fim, mas não menos importante, a diversidade do portfólio foi garantida assumindo-se a premissa de que para cada segmento de mercado no máximo dois projetos (os melhores avaliados) poderiam ser escolhidos, e desde que as soluções tecnológicas propostas fossem substancialmente diferentes entre si.

Quadro 8 - Quesitos de Avaliação dos Projetos Finalistas

Capacitação da equipe proponente (para implementar o projeto/negócio proposto)

Atratividade (do mercado e/ou do produto/tecnologia)

Capacidade de geração de receita

Caráter inovador (da tecnologia; do produto ou do modelo de negócio)

Sinergia com os mercados da Corporação

Fonte: Elaborado pelos autores (2016)

\subsection{O Portfólio}

O resultado final do processo foi um portfólio de 10 startups, das quais três foram classificadas como investimentos conservadores (baixo risco/retorno), quatro arrojados (alto risco) e três intermediários (Figura 4). Os projetos apresentaram diversidade tanto em temos de segmentoalvo (logística; serviços; manufatura; agronegócio; educação e comércio) quanto em tecnologias (dispositivos móveis; imersão 3D; computação em nuvem) e modelos de negócio.

Figura 4 -Distribuição das startups selecionadas por grau de risco

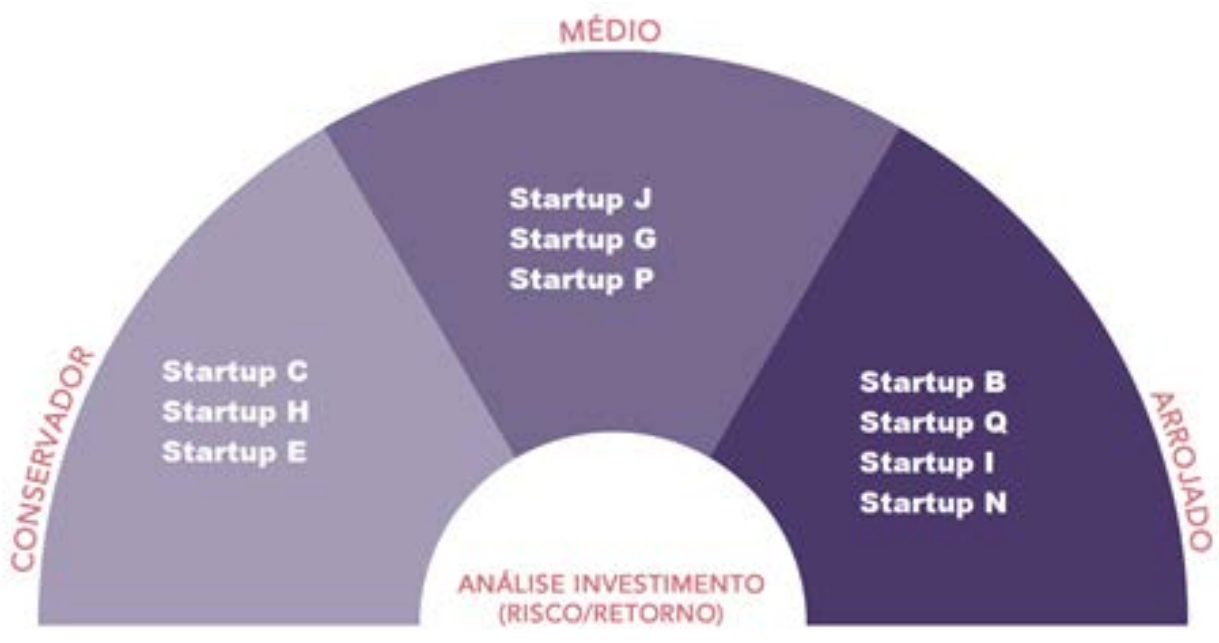

Fonte: Elaborado pelos autores (2016)

${ }^{3}$ Sob a ótica financeira, geralmente há uma correlação entre risco e potencial de retorno. A possibilidade de auferir grande retorno sobre o investimento está associada a correr maiores riscos, quer sejam tecnológicos, mercadológicos ou financeiros. 


\section{DISCUSSÃO}

O caso apresentado utilizou a abordagem e fez uso de diferentes técnicas de GPP. Nas fases iniciais do processo de seleção, listas de verificação e scoring models foram utilizadas para descartar ou para selecionar os projetos candidatos. Diagramas de bolha ajudaram os tomadores de decisão a rapidamente visualizarem a classificação do portfólio - segundo diferentes critérios de análise. Nas fases finais, baldes (ou envelopes) estratégicos garantiram a escolha de um portfólio balanceado em termos da relação risco versus retorno (perfil de investimento).

Pode-se dizer que ao adotar GPP o objetivo do processo de seleção foi muito além de ranquear e escolher projetos a partir de notas ou avaliações a eles atribuídas, uma vez que incorporou como meta a seleção de uma carteira de projetos que maximizasse - simultaneamente - o (potencial de) retorno do investimento e a aderência ao maior número de direcionadores tecnológicos e mercadológicos.

Os resultados alcançados, ou seja, a carteira de projetos demonstra que esses objetivos foram cumpridos.

\subsection{Conclusão}

O estudo sugere que GPP pode ser uma abordagem indicada para balizar o processo de análise e seleção de startups alvos de CVC, algo que a literatura aponta como um de seus maiores desafios (CHESBROUGH, 2002).

A possibilidade de se realizar análises baseadas em critérios subjetivos e sob diferentes perspectivas foi essencial para o processo aqui relatado, especialmente em função do alto grau de incerteza dos empreendimentos - a maioria deles em estágio muito inicial, o que inviabilizaria avaliações mais objetivas - quer sejam baseadas em VPL ou qualquer outro instrumento quantitativo.

\subsection{Limitações e trabalhos futuros}

Um caso bem-sucedido aponta uma perspectiva interessante, mas é insuficiente para sugerir que seja uma solução generalizável. Dessa forma, em que pese as evidências que apontam GPP como abordagem alinhada com os desafios de investimento no contexto do CVC, novos estudos de caso podem tanto reforçar as conclusões deste estudo quanto suscitar novas questões para análise.

Além disso, o estudo aborda apenas a fase de construção inicial da carteira de projetos. Há oportunidades de estudos sobre a gestão proativa do portfólio de projetos, ao longo do tempo, ou seja, descarte, priorização ou incorporação de novos projetos à carteira.

Um amplo conjunto de estudos sobre aplicação de GPP em atividades de CVC ajudaria a compilar o conhecimento necessário para a construção de um modelo genérico e balizado em evidências científicas. 


\section{REFERÊNCIAS}

ALLMAN, A. R.; CAN, W.; YOU, S. Spotlight on Innovation For the 21 st Century. Harvard Business Review, v. 86, n. 5, p. 66-76, 2012.

ANTHONY, Scott. The New Corporate Garage. Harvard Business Review, v. 90, n. 9, p. 45-53, 2012.

ARRUDA, Carlos et al. Towards an understanding of corporate venturing practices in Brazil. Venture Capital: An International Journal of Entrepreneurial Finance, v. 15, n. 2, p. 135-149, 2013.

CHAO, R. O.; KAVADIAS, S. A Theoretical Framework for Managing the New Product Development Portfolio: When and How to Use Strategic Buckets. Management Science, v. 54, n. 5, p. 907-921, 2008.

CHESBROUGH, H. W. Making sense of corporate venture capital. Harvard Business Review, v. 80, n. 3, p. 90-99, 2002.

COOPER, R. G.; EDGETT, S. J.; KLEINSCHMIDT, E.J. New Problems, New Solutions: Making Portfolio Management More Effective. Research Technology Management, v. 43, n. 2, p. 18-33, 2000. COOPER, R. G., EDGETT, S. J.; KLEINSCHMIDT, E. J. Portfólio management for new products. New York: Perseus Books, 2001.

COOPER, R. G.; EDGETT, S.J. Portfólio management for new products: picking the winners. Working Paper n.11. Product Development Institute. (online), 2006. Disponível em: <http://www. stage-gate.net/downloads/working_papers/wp_11.pdf>. Acesso em: 26 nov. 2014.

COUGHLAN, P.; COGHLAN, D. Action Research for Operations Management. International Journal of Operations and Production Management, v. 22, n. 2, p. 220-240, 2002.

GASSMANN, O.; BECKER, B. Towards a Resource-Based View of Corporate Incubators. International Journal of Innovation Management, v. 10, n. 1, p. 19-45, 2006.

HISRICH, R. D.; PETERS, M. P. Establishing a new business venture unit within a firm. Journal of Business Venturing, v. 1, n. 3, p. 307-322, 1986.

IRELAND, R. D.; COVIN, J. G.; KURATKO, D. F. Conceptualizing Corporate Entrepreneurship Strategy. Entrepreneurship Theory and Practice, v. 33, n. 1, p. 19-46,

2009.

KURATKO, D. F.; COVIN, J. G.; GARRETT, R. P. Corporate entrepreneurship \& innovation. Mason, $\mathrm{OH}$ : Cengage/South-Western Publishers, 2008.

KURATKO, D. F.; COVIN, J. G.; GARRETT R. P. Corporate Venturing: Insights from actual performance. Business Horizons, v. 52, n. 5, p. 459-467, 2009.

LARA, Alexander P. ; CHENG, L. C. . A proposal for the management of software products aiming at the elaboration of innovation-based competitive strategies. Product (IGDP), v. 7, p. 91-101, 2009.

MANDEL, Michael. Scale and Innovation in Today's Economy. [2011]. Disponível em: <http:// progressivepolicy.org/wp-content/uploads/2011/12/12.2011-Mandel_Scale-and-Innovation-inTodays-Economy.pdf >. Acesso em: 11 ago. 2016.

MCGRATH, Michael E. Product Strategy for high technology companies. 2. ed. Columbus: McGraw-Hill, 2000.

MORRIS, M.; KURATKO, D.F.; COVIN, J. G. Corporate Entrepreneurship \& Innovation: Entrepreneurial Development within Organizations. Mason-Ohio: South-Western Cengage Learning, 2008. 
POZIN, Ilya. 3 Things to Know About Corporate Venture Capital. [2014]. Disponível em < http:// www.inc.com/ilya-pozin/3-things-to-know-corporate-venture-capital.html >. Acesso em: 09 mar. 2016.

QUITTNER, Jeremy. What's Really Driving the Boom in Corporate VC Firms. [2014]. Disponível em < http://www.inc.com/jeremy-quittner/corporate-venture-capital-drives-innovation-for-bigcompanies.html >. Acesso em: 09 mar. 2016.

SATHE, Vijay. Corporate Entrepreneurship: Top Managers and New Business Creation. Cambridge: Cambridge University Press, 2003.

THIOLLENT, M. Metodologia da Pesquisa-Ação. São Paulo: Cortez, 1996.

URHAHN, C.; SPIETH, P. Governing the Portfolio Management Process for Product Innovation-A Quantitative Analysis on the Relationship Between Portfolio Management Governance, Portfolio Innovativeness, and Firm Performance. IEEE Transactions on Engineering Management, v. 61, n. 3, p. 522-533, 2014.

VÄHÄNIITTY, J.; RAUTIAINEN, K. Towards an Approach for Development Portfólio Management in Small Product-Oriented Software Companies. In: Hawaii International Conference on System Sciences, 38., 2005. Proceedings... Big Island: HI USA, 2005. p. 01-10. 